\title{
25 YEARS OF THE COMMITTEE OF THE REGIONS AND ITS IMPACT ON THE EU LEGISLATIVE PROCESS: REMARKS IN THE LIGHT OF THE CONCEPT OF MULTILEVEL GOVERNANCE IN THE EU
}

\begin{abstract}
In 2020 , the $25^{\text {th }}$ anniversary of the Committee of the Regions - the representative body of the EU's local and regional authorities is celebrated. Its main goal is to represent the interests of local government at the level of this international organization, to increase the democratic mandate of the EU, as well as to increase the transparency of public debate between European institutions.

A quarter of a century is a good time to try to evaluate the actions taken by this EU body. The purpose of this article is to conduct a legal analysis of the evolution of EU primary law in its functioning, to summarize that functioning, as well as its impact on the EU legislative process. The article will also present a proposal for its development in coming years.
\end{abstract}

\section{Key words}

Committee of the Regions, European Union, local government, multilevel governance $\mathrm{EU}$ 


\section{Introduction}

The system of creating public policies within the EU political system is extremely complicated, both in terms of the horizontal and vertical division of competences and the decision-making procedures themselves. What is more, consideration should be given to allowing non-public entities into these mechanisms through a wide range of access paths. Hence, the EU multilevel governance (EU MLG) concept is currently becoming the basic model for analyzing EU policies. In principle, the term refers to the dispersion of competences for making public decisions, shifting them from state central government "up" to the supra-national level and "down" to the sub-state level. What is important, however, it is also to take place simultaneously in the horizontal plane through its distribution within private-public networks of public policies. Today there is no doubt that contacts and cooperation of entities, which could each be at different levels of this multilevel structure, is also possible (Ruszkowski \& Wojnicz, 1992).

The European Committee of the Regions (CoR) is one of the bodies to take on the burden of including non-governmental entities in EU decision-making processes. The assumption is that it will be a platform for representing and transferring the interests of local governments - as structural units of the EU system - as part of decision-making processes above the national level in the EU. Despite the passage of years from its introduction, it should be seen as a specific solution on a global scale for international organizations of the inter-state type. Therefore, as part of the study, the author intends to seek answers to the questions: what the legal legitimacy for CoR participation in the EU decision-making process is; and whether it can be considered to satisfactorily allow representation of the interests of local and regional authorities within the EU MLG. The main method used to conduct this study is an analysis of sources, especially documents and statistical data. Sources of information will include the author's research, as well as his own experience acquired through various social and public functions.

\section{Evolution of the legal basis for the functioning of the CoR}

The CoR was set up under the Maastricht Treaty, which defines its composition, tasks, competences, members selection procedure, procedures for issuing opinions and the types of opinion (Calussi, 1998, pp. 225-249). Its establishment was a response to a crisis of democratic legitimacy in the European project that 
was emerging as the EU and the CoR has become more than just a representative body of local and regional authorities. The EU had to be understood as more than just a community of states. The CoR was a symbol of legitimized entities at a level other than government representatives or elected members of the European Parliament (EP) in shaping the public policies of the EU (Christiansen, 1996, p. 106). The President of the EC, Jacques Delors, during the first plenary session of the CoR stated that this is the superior function of this body, and that the task of the CoR is to do nothing but strengthen the democratic legitimacy of the EU. The CoR is so important as it can fill the gap. First, the activities of the CoR will bring the EU's activity closer to local reality. The committee will be a link between local problems and bottom-up reactions. Secondly, the CoR will explain EU policies to people in the regions (CoR, 2014, p. 9).

Article 198a of the Maastricht Treaty established that the CoR was composed of representatives of local and regional authorities appointed unanimously by the Council (Warleigh, 1997, pp. 101-107). Nominations for members and an equal number of alternates were submitted by member states. The members and alternates of the CoR exercise their mandate independently and are not bound by any instructions. Their mandate is renewable.

In accordance with the treaty provisions, the CoR elected its chairman and presidium for a two-year term from among its members. The CoR was also obliged to adopt its rules of procedure which required the unanimous approval of the Council. Meetings were convened by the chairman at the request of the Council or the European Commission (EC) but the CoR also had the power to convene a meeting on its own initiative (TEU, 1992, art. 198b).

The Treaty on European Union (TEU), which entered into force on November 1, 1993, established three modes of "opinion" for the CoR: obligatory, optional or on its own initiative.

Mandatory consultation with the CoR was required as provided for in the Maastricht Treaty which provided for seven cases:

- Art. 126 section 4, in the field of education and youth;

- Art. 128 section 5, in the field of culture;

- Art. 129 section 4, in the field of public health;

- Art. 129d, in the field of trans-European transport, electricity and telecommunications infrastructure networks;

- Art. 130b, in the field of economic and social cohesion;

- Art. 130d, in the field of structural funds;

- Art. 130e, in the field of the European Regional Development Fund. 
Under the Maastricht Treaty, the institutions of the EU were obliged to consult draft documents in seven areas: education and youth, culture, public health, trans-European networks, economic and social cohesion, structural funds and the European Regional Development Fund. The subject scope of obligatory consultation is not accidental as these areas are closely related to the competences of local and regional governments in the EU. Local governments are mostly responsible for the proper implementation of tasks in these areas.

Optional consultation with the CoR took place on the basis of art. 198c of the TEU, in other words, when the EC or the Council found it justified. or in the case of their consultations with the Economic and Social Committee, when the CoR considers that the material scope of the case is of particular importance for regional interests (TEU, 1992, art. 198c).

The CoR has also been given the right to issue own-initiative opinions in cases where it considers it appropriate (TEU, 1992, art. 198c). At the same time, the CoR pursuant to art. 198c of the TEU was obliged to send these opinions, together with the minutes of meetings, to the EC and the Council.

Thanks to the provisions of the Maastricht Treaty, local and regional authorities received a direct "access channel" to EU lawmaking procedures in which the CoR became an independent advisory body to the Council and the EC with specific competences. The institutions of the EU were obliged to consult certain areas of its activity. Under Protocol 16 to the TEU the CoR had a common organizational structure with the Economic and Social Committee. Taking this into account, it should also be noted that the introduction of the CoR was an extremely innovative solution as a concept for shaping public policies in international inter-state organizations such as the EU. The CoR has become an additional platform for representing the interests of local governments in the EU's decision-making processes.

Given the dynamics of the integration process, however, it quickly became apparent that the solutions adopted needed some changes. The reasons included expanding the integration process to include further countries, as well as its deepening, noticeable despite increasing the powers of the EP. In addition, the scope of tasks for local and regional authorities in the implementation of public policies increased which also forced reforms on the CoR. In the end, it is hard to ignore the declared willingness to listen to EU decision-makers directly in problems occurring at a level as close to EU citizens as possible.

The first amendments to the provisions regarding the CoR, except for the accession treaties where the number of members and their alternates were changed, were through the Treaty of Amsterdam. The changes introduced can be divided 
into two groups: the first concerns the scope of CoR activities, while the second deals with organizational and structural changes.

As part of the changes related to the scope of CoR activities: the range of obligatory consultation was increased, the EP was added to the institutions that could consult the CoR, and cross-border cooperation was included as an optional consultation.

Pursuant to the provisions of art. 2 para. $49 \mathrm{~b}$ of the Treaty of Amsterdam, article 198c of the TEU was amended, adding the EP to institutions that may consult the CoR: "after the third paragraph, the following paragraph shall be inserted: 'The Committee of the Regions may be consulted by the European Parliament"” (Treaty of Amsterdam, 1997, art. 2 para. 49b).

Mandatory consultation with the CoR has been extended to include the following areas:

- Article 74 TEU - transport;

- Article 109q TEU para. 2 and 109 TEU - employment;

- Article 118 para. 1 and 2 TEU - social policy;

- Article 125 TEU - European Social Fund;

- Art. 130s TEU - natural environment.

Article 198c of the TEU on optional consultation has been amended. Pursuant to art. 2 para. 49 , the phrase "in particular those which concern cross-border cooperation, in which one of these two institutions considers it appropriate" was added to the Treaty of Amsterdam. Protocol 7 on the principles of subsidiarity and proportionality was also added, which obliged the EC to submit annual reports to the CoR.

As part of the second group of organizational and structural changes introduced by the Treaty of Amsterdam, the CoR, among others, gained organizational independence, was given a permanent seat and the possibility of selfdetermination of internal regulations. Pursuant to art. 2 para. 59 of the Treaty of Amsterdam, protocol no. 16 to the TEU, the joint organization of the Economic and Social Committee and the CoR was repealed. Thus, the CoR gained organizational independence from the Economic and Social Committee. Article 2 para. 48 of the Amsterdam Treaty the content of art. 198b TEU was amended to: "It shall adopt its Rules of Procedure". From that moment, the CoR had complete freedom to create and amend its own internal regulations which did not require further approval by the Council.

The Treaty of Amsterdam (1997) also introduced a provision prohibiting the merging of the mandate of a member of the EP with the mandate of a member or deputy of the CoR: "No member of the Committee shall at the same time 
be a Member of the European Parliament" (Art. 2 para. 47). The last change regarding the $\mathrm{CoR}$ is the establishment of its permanent seat. Under Protocol $12 \mathrm{~g}$ (1997) the CoR has its seat in Brussels.

The next reform, called the Treaty of Nice, did not significantly change the functioning of the CoR. All in all, this was not its main purpose as its task was to prepare the institutional system for the largest expansion in EU history. In this spirit, treaty provisions devoted to the CoR were changed.

Article 2 para. 42 of the Treaty of Nice changed article 263 of TEU dedicated to the CoR. Under the new provisions, the CoR consists of representatives of local or regional authorities who have the mandate of a local or regional community, or who are politically responsible to the elected assembly. The mandate based on which a candidate became a member or deputy of the CoR by law was lost. This regulation was aimed at binding the mandate of a member with representatives of local or regional authorities elected in general elections or elected by assemblies with a mandate from a general election. The acceptance of candidates for members and deputies of the CoR on the basis of lists by member states was left to the Council, which decided it by qualified majority, not unanimously as before. Other issues related to the renewal of the mandate, independence, non-binding instructions, the inability to combine the mandate of a member of the CoR, and the term of office have remained unchanged. The maximum number of members on the CoR was also set at 350 seats. Declaration no. 20 was attached to the Treaty of Nice, dividing CoR seats between present and future member states of the EU (Christiansen \& Linter, 2005, pp. 7-13).

Recent treaty changes dedicated to the CoR were made by the Treaty of Lisbon. The amended TEU explicitly states that the CoR is an advisory body: "The European Parliament, the Council and the Commission shall be assisted by an Economic and Social Committee and a Committee of the Regions, exercising advisory functions" (Christiansen \& Linter, 2005, pp. 7-13). An identical entry was repeated in art. 300 para. 1 of the Treaty on the Functioning of the EU (TfEU) in chapter 3, "Advisory bodies".

According to the provisions of art. 305 of the TfEU, the election of members to the CoR will be made by the Council, by unanimous decision on a proposal from the EU. In terms of organizational and structural matters: the term of office of the CoR has also been extended to 5 years (TfEU, 2012, art. 305), and thus the term of office of the president and presidium from 2 years to 2.5 years (TfEU, 2012, art. 306). The CoR was given the opportunity to convene meetings at the request of the EP, and the maximum number of 350 members was 
also maintained; it was, however, not split up between respective member states (TfEU, 2012, art. 306).

The CoR gained new powers thanks to a reform of primary law introduced by the Lisbon Treaty (TfEU, 2012, art. 306). Pursuant to art. 263 of the TfEU in relation to art. 8 of Protocol no. 2 on the application of the principles of subsidiarity and proportionality, a complaint may be lodged with the EU Court of Justice "against legislative acts for the adoption of which the Treaty on the Functioning of the European Union provides that it be consulted" (Protocol no. 2, 1997, art. 8).

\section{Selected aspects of CoR activities}

The main area of activity of the CoR is the advisory function (Labitzke, 2012, pp. 323-336) towards the EP, the Council and the EU (TfEU, 2012, art. 300 para. 1). In this respect, despite the systemic transformations in the processes of creating public policies within the MLG EU, the way in which its basic function is fulfilled has not changed fundamentally. It is implemented by issuing obligatory, optional or own-initiative opinions (TfEU, 2012, art. 300 para. 1).

Fig. 1. Number of opinions issued by the CoR: 1994-2018

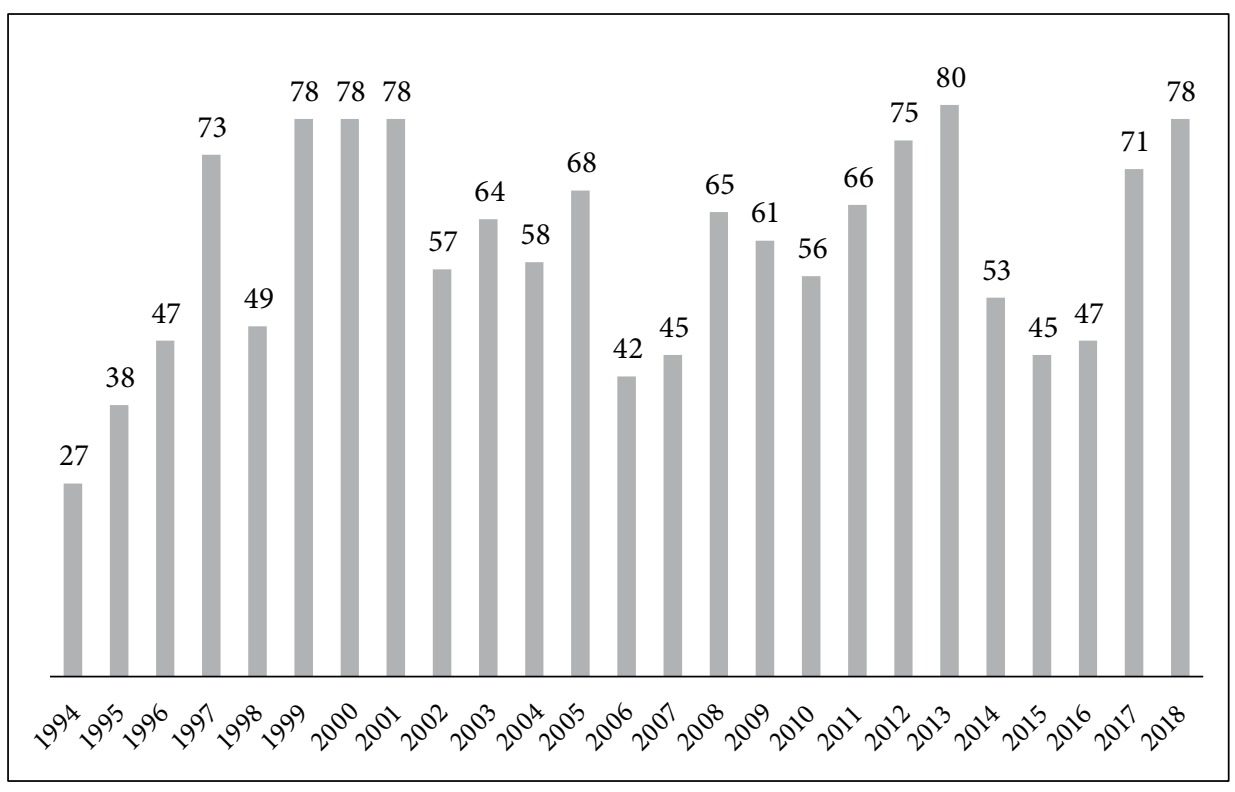

Source: own compilation based on minutes of plenary sessions of the CoR. 
To a large extent, the number of opinions issued by the CoR has depended on the legislative activity of its institutions. Based on the above graph, a certain cyclical nature and intensification with a larger number of opinions received at specific moments can be observed. The smallest number were issued during a period when the new term of the EC begins which seems obvious and can be treated as a specific element of EU governance.

Fig. 2. Summary of CoR opinions by type of consultation

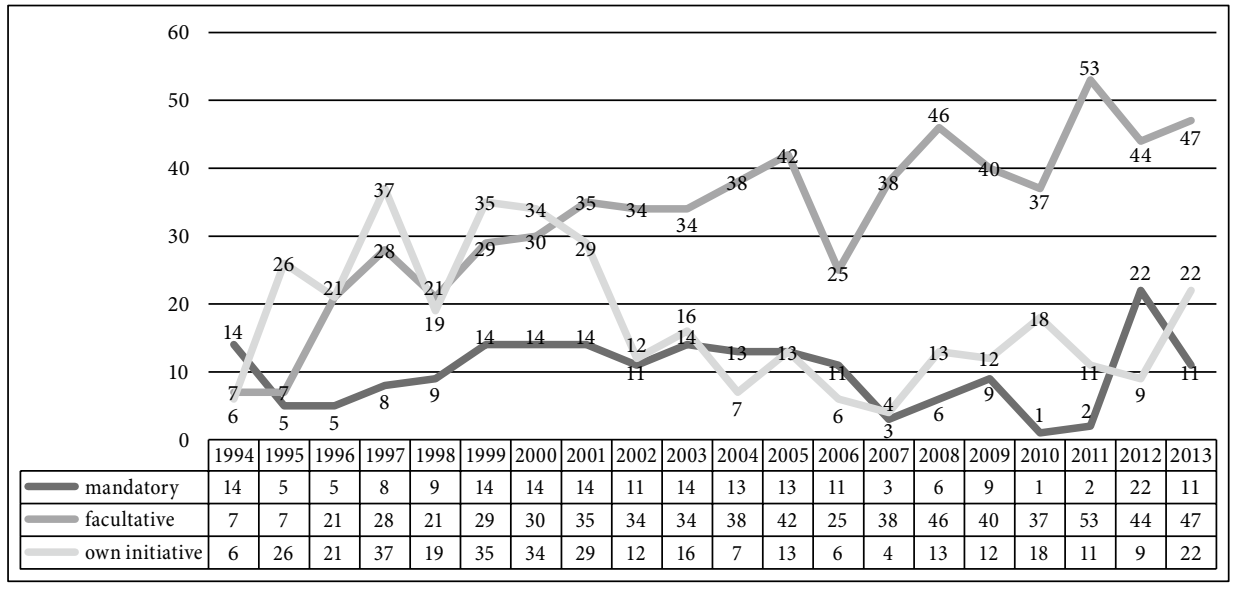

Source: own research, based on the minutes of CoR plenary sessions.

The CoR has no influence on how many mandatory or optional opinions it issues, however, it has an impact on own-initiative opinions. The graph above shows that when EU institutions did not request an opinion, this body on its own initiative increased its activity. This should be read as a sense of responsibility of its members for the quality of decisions made within the framework of the EU MLG.

In this light it should be seen that in order to more effectively implement its fundamental task the CoR has concluded a cooperation agreement with the EC (Protocol, 2012) and the EP (Agreement EP/CoR). Unfortunately, there is not even a draft agreement yet between the Council and the CoR.

The activities of the CoR are not limited to giving opinions on draft acts submitted by EU institutions. It has initiated many projects and activities aimed at increasing the activity of local governments and citizens at the European level. The CoR also promotes cross-border dialogue and cooperation and has had a significant impact when creating the European Grouping of Territorial 
Cooperation, where the amendments proposed to the draft regulation were taken into account by the institutions of the EU (CoR, 2005, p. 46). At the same time, the EU body has many international cooperation networks, including the CoR Europe 2020 Monitoring Platform, the Subsidiarity Monitoring Network, and the Network of Regional Hubs for EU Policy Implementation (RegHub).

Another factor indicating a steady increase in the activities carried out by the CoR may also be the amount of funds at the disposal of this body.

Fig. 3. Budget for the CoR: 2000-2014

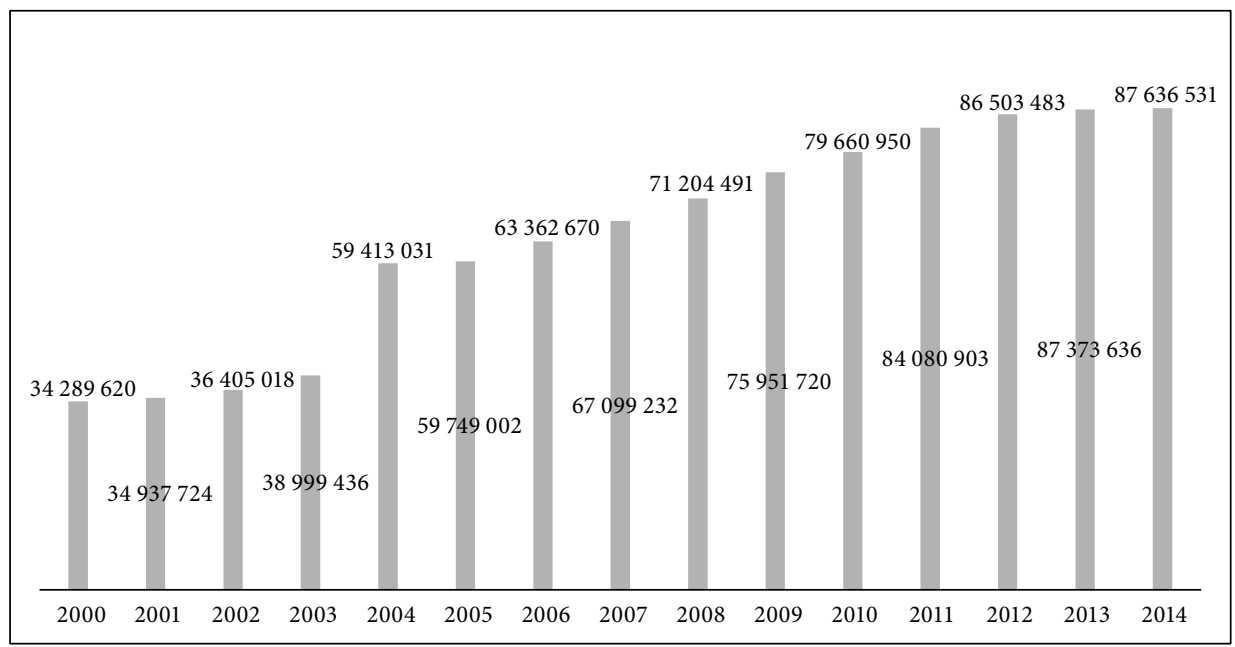

Source: based on materials made available by the CoR.

As the graph above shows, the budget of the CoR is increasing every year. This is due not only to its greater involvement in public debate, but also to an intensification of activities. It should be mentioned here that a detailed analysis of financial data may direct attention to the fact that the higher costs of maintaining employment in its administration are also an important element of the budget increase.

Over the years analyzed (Table 1), employment costs increased by just over $13 \%$. The growing tendency to engage in public discussion, promote participation and finally prepare opinions, however, should be interpreted as an increase in expenditure on activities related to its treaty tasks. All the more so considering that exactly the same increase $(13 \%)$ can be seen in terms of expenditure on political activities. On other items, the CoR's budget has changed slightly. It should also be noted that - unlike, for example, members of the EP - members 
of the CoR do not receive any remuneration. They can only count on reimbursement of travel expenses and a fixed sum for attending a meeting which undoubtedly reduces its operating costs. This means that it does not generate excessive costs for the EU budget by carrying out important tasks from the EU MLG perspective.

Table 1. Statements of expenditure under the CoR budget

\begin{tabular}{|c|c|c|c|c|c|c|c|}
\hline year & $\begin{array}{c}\text { Employment } \\
\text { costs }\end{array}$ & $\begin{array}{c}\text { Rent and } \\
\text { lease of } \\
\text { buildings }\end{array}$ & $\begin{array}{c}\text { Building } \\
\text { mainte- } \\
\text { nance costs }\end{array}$ & $\begin{array}{c}\text { Political } \\
\text { activity }\end{array}$ & $\begin{array}{c}\text { Press and } \\
\text { commu- } \\
\text { nication }\end{array}$ & $\begin{array}{c}\text { Other } \\
\text { expenses }\end{array}$ & Total \\
\hline $\mathbf{2 0 0 7}$ & 37051794 & 8068510 & 3200288 & 10777197 & 1683000 & 6318443 & $\mathbf{6 7 0 9 9 2 3 2}$ \\
\hline $\mathbf{2 0 0 8}$ & 39735370 & 7722800 & 3951980 & 10888653 & 1705000 & 7200688 & $\mathbf{7 1 2 0 4 4 9 1}$ \\
\hline $\mathbf{2 0 0 9}$ & 42755410 & 8785651 & 4047688 & 11490313 & 1802100 & 7570558 & $\mathbf{7 6 4 5 1 7 2 0}$ \\
\hline $\mathbf{2 0 1 0}$ & 43937109 & 9179654 & 4484140 & 12236665 & 1790622 & 8032760 & $\mathbf{7 9 6 6 0 9 5 0}$ \\
\hline $\mathbf{2 0 1 1}$ & 46339494 & 9208315 & 4492892 & 13553151 & 2044086 & 8442965 & $\mathbf{8 4 0 8 0 9 0 4}$ \\
\hline $\mathbf{2 0 1 2}$ & 48278885 & 9470663 & 4641547 & 13819211 & 2080068 & 8213109 & $\mathbf{8 6 5 0 3 4 8 3}$ \\
\hline $\mathbf{2 0 1 3}$ & 48990856 & 9876011 & 4593791 & 13843317 & 1976065 & 8093596 & $\mathbf{8 7 3 7 3 6 3 6}$ \\
\hline $\mathbf{2 0 1 4}$ & 49264552 & 9987194 & 4541267 & 14035379 & 1940565 & 7867574 & $\mathbf{8 7 6 3 6 5 3 1}$ \\
\hline
\end{tabular}

Source: based on materials made available by the CoR.

During its 25 years of activity, the CoR has significantly marked its position in the institutional system of the EU. The scope of obligatory consultation of legislative acts handled by the EU institutions has increased, it has obtained the right to lodge a complaint to the Court of Justice of the EU in order to protect its prerogatives, it has the right to self-determination of its internal regulations, and it has gained organizational and financial independence. This can be seen as an increase in the importance of the CoR in the processes taking place in the EU MLG. However, this problem should be viewed differently if one considers other changes taking place within the system of shaping EU public policies. Over the years and the ongoing reforms, other bodies representing entities other than the governments of member states have gained in importance. Above all, it is about the EP which became an equal participant of the EU Council in the process of legislating at the supra-national level. Another example is that the EC has significantly become open - through increasingly common open internet consultation procedures - to the impact of various external entities, including local government units. It can therefore be said that after the political changes, the CoR gives a greater chance for an influence of local government units on 
decision-making processes in the EU MLG than at the time of its establishment. Nevertheless, it should be remembered that in this period other, often more effective, access paths to the processes of shaping public policies have been created, both for local and regional authorities, as well as EU citizens themselves.

\section{Summary}

The 25 years of operation of the CoR has shown that it has not become just a body for issuing opinions, but above all it has become a platform for cooperation and exchange of experience between the local and regional authorities of the EU. The CoR has become strongly involved in the discussion on European issues and has become an effective channel for informing citizens about the changes taking place in the EU.

An undoubted factor contributing to the success of this body's activities are its members. Local government representatives with a strong social mandate allow for building an effective debate based on their authority. An interesting element of the CoR's activities is active involvement in the development of the principle of a multi-level management system, and this becomes more and more important every year. Including entities at various levels (local, regional) as well as their legal nature (foundations, associations, natural persons) in their activities gives these a chance to take part in the processes of creating public policies in the EU. At the same time, the CoR, becoming a platform for information exchange, gains the benefits it needs to carry out its tasks which is knowledge of entities interested in the effect of its activities.

However, the question remains whether the kind of powers the CoR has at its disposal should be considered sufficient in the current reality of creating public policies within the EU MLG. The number of challenges facing local governments as part of operating within EU structures is increasing. Their importance is growing in the processes of implementing public policies created under the EU system. This is the same as the level of funds involved in implementing public policies for which sub-governmental entities are often responsible. This can be considered as arguments in favor of strengthening the voice of local government units in the processes of shaping public policies within the EU MLG. On the other hand, the idea behind the role of the CoR does not significantly change. It will be acknowledged that consultative participation in the lawmaking process, as well as a developed information function towards other entities, may now appear to be small tools for influencing the decision-making process for the CoR - the body that represents local and regional authorities so important 
in the process of implementing public policies the EU. At the same time, which should be borne in mind, the formal and legal competences of the EP are increasing, as well as the degree of participation of national parliaments in creating law at supra-national levels in the EU, i.e. bodies directly representing the interests of citizens. Therefore, the legitimate question is whether the current formal and legal mandate of the CoR corresponds to the responsibility of the entities it is supposed to represent, and whether it conforms to the current shape of the division of powers to legislate above the national level in the EU.

The author does not claim the right to solve this dilemma, it also exceeds the research assumptions of this work. It is worth emphasizing, however, that for some time extreme concepts have often emerged regarding the systemic future of the CoR. On the one hand, there is the need for its liquidation or marginalization, on the other, the need to increase its position, e.g. by making it a higher chamber of the EP. Certainly, the future of the CoR will be the subject of serious political debate in the EU. Its performance and results are not only a matter for local and regional authorities, but also for the smooth functioning of the EU's MLG.

\section{REFERENCES}

Baliu, M. K. (2008). Better Regulation for EU Regions: A Reflection on the Impacts of EU Regulations on the Regions. EIPAScope, 2, 1-5.

Calussi, F. B. (1998). The Committee of the Regions, An Atypical Influential Committee? In M. P. C. M. van Schendelen (ed.), EU Committees as Influential Policymakers (pp. 225-249). Aldershot: Ashgate.

Christiansen, T. (1996). Second Thoughts on Europe's "Third Level": The European Union's Committee of the Regions. Publius: The Journal of Federalism, 26(1), 93-116.

Christiansen, T., \& Lintner, P. (2005). The Committee of the Regions after 10 Years: Lessons from the Past and Challenges for the Future. EIPASCOPE, 7, 7-13.

Committee of the Regions. (n.d.). A new treaty: a new role for regions and local authorities. Retrieved from https://cor.europa.eu/en/our-work/Documents/Our-work/ lisbon-treaty.pdf

Committee of the Regions. (2014). Milestones in the history of the Committee of the Regions 1994-2014. Retrieved from https://cor.europa.eu/en/engage/brochures/Documents/milestones-in-the-history-of-CoR/milestones-in-the-history_English.pdf

Committee of the Regions. (2005). Opinion of the Committee of the Regions on the Proposal for a Regulation of the European Parliament and of the Council establishing a European grouping of cross-border cooperation (EGCC), EurLex: 52004AR0062. 
Cooperation Agreement between the European Parliament, the European Economic and Social Committee and the Committee of the Regions, 5 Feb. 2014. Retrieved from https://www.eesc.europa.eu/en/documents/cooperation-agreement-betweeneuropean-parliament-eesc-and-cor

Labitzke, J. (2012). Consultation Processes as a Practice of Legitimacy in the EU Legislative Process. Journal of Contemporary European Studies, 20(3), 323-336.

Protocol no. 2 on the application of the principles of subsidiarity and proportionality, EurLex: 12012M/PRO/02.

Protocol on cooperation between the European Commission and the Committee of the Regions. (2012), EurLex: 32012Y0405(02).

Protocol on the application of the principles of subsidiarity and proportionality, $2 \mathrm{Oct}$ 1997, EurLex: 11997D/PRO/07.

Protocol on the location of the seats of the institutions and of certain bodies and department of the European Communities and of Europol, 2 Oct 1997, EurLex: 11997D/ $\mathrm{PRO} / 07$.

Ruszkowski, J., \& Wojnicz, L. (eds.). (1992). Multi-level governance w Unii Europejskiej. Szczecin-Warszawa: Instytut Politologii i Europeistyki Uniwersytetu Szczecińskiego, Instytut Europeistyki Uniwersytetu Warszawskiego.

Treaty of Amsterdam Amending the Treaty on European Union, the Treaties Establishing European Communities and Certain Related Acts, 2 Oct 1997, EurLex: 11997D/ TXT.

Treaty of Nice amending the Treaty on European Union, the Treaties establishing the European Communities and certain related acts, 26 Feb 2001, EurLex: 12001C/ TXT.

Treaty on European Union, 7 Feb 1992, EurLex:11992M/TXT.

Treaty on the Functioning of the European Union (TfEU, consolidated version), 13 Dec 2007, EurLex: C2012/326/01.

Warleigh, A. (1997). A Committee of No Importance? Assessing the Relevance of the Committee of the Regions. Politics, 17(2), 101-107. 